\title{
CORPO DE BOMBEIROS MILITAR DE PERNAMBUCO: UM ESTUDO DE CASO SOBRE AS FONTES DE RECURSOS E A VIABILIDADE DE UM FUNDO PÚBLICO ESPECÍFICO
}

\author{
Bruno Luiz do Nascimento Silva Santos ${ }^{1}$ \\ Fernando Gentil de Souza ${ }^{2}$
}

\section{RESUMO}

Este estudo tem como principal objetivo analisar as fontes de recursos do Corpo de Bombeiros Militar de Pernambuco (CBMPE) e suas destinações no período de 2013 a 2017 para verificar a viabilidade de um fundo público. O contexto de crise econômica e fiscal dos Estados demanda políticas mais assertivas de alocação de recursos públicos. Para elaboração deste estudo empírico foi adotado metodologia estruturalista com análise descritiva documental, considerando os informação orçamentária disponível na página web do Portal da Transparência. Os resultados indicam que no período analisado teve maior financiamento da atividade mediante recursos de fontes originárias do Estado: Fundo de Participação do Estado, mostrando maior dependência do ente centralizador. Destaca-se o ano 2017, quando cerca de $70 \%$ das fontes se referiram aos recursos arrecadados mediante suas próprias taxas. Esta mudança na alocação de recursos ocorreu no período da publicação da Estrutura Conceitual aplicada ao Setor Público que introduziu conceitos sobre as receitas de transação sem contraprestação e a característica de restrição para informação contábil. Finalmente, conclui-se que a existência da relação entre as taxas (receitas de transação sem contraprestação) e o fundo público pode ser utilizada como justificativa para a sua criação e vinculação dos recursos na atividade que origina a respectiva taxa.

Palavras-chave: Corpo de Bombeiros Militar de Pernambuco; Taxas públicas; Fundos Públicos; Receitas de Transação sem Contraprestação; Restrição.

\footnotetext{
${ }^{1}$ Oficial do Corpo de Bombeiros Militar de Pernambuco. Bacharel em Ciências Contábeis, pela Universidade Federal de Pernambuco - UFPE.

${ }^{2}$ Professor Doutor de Ciências Contábeis da Universidade Federal de Pernambuco - UFPE.
} 


\title{
MILITARY FIRE BRIGADE OF PERNAMBUCO: CASE STUDY ON ORIGIN OF RESOURCES AND SPECIFIC PUBLIC FUND'S FEASIBILITY
}

\begin{abstract}
This study has as main objective to analyze origin of resources of the Military Fire Brigade of Pernambuco (CBMPE) and its allocations from 2013 to 2017 to verify the viability of a public fund. The economic and fiscal crisis in the Brazilian states demands policies more assertive allocation of public resources. For preparation of this empirical study, a structuralist methodology was adopted with a descriptive documentary analysis, considering the budget information available in Transparency website. Results indicate that analyzed period had greater financing of activity through resources from State sources originating: State Participation Fund, showing greater dependence on centralizing entity. Of note is the year 2017, when about $70 \%$ of sources referred to resources collected from their own fees. This change in allocation of resources occurred in period of publication of Conceptual Framework applied to public sector, that introduced concepts about Revenue from Exchange Transaction and restriction characteristic for accounting information. Finally, it is concluded that the existence of the correlation between rates (non-negotiated transaction revenues) and public fund can be used as justification for their creation and linking the resources in the activity that gives rise to the respective rate
\end{abstract}

Keywords: Military Fire Brigade of Pernambuco. Public Fees. Public Funds. Revenue from non-Exchange Transactions. Restrictions.

Artigo Recebido em 15/01/2019 e Aceito em 30/07/2019 


\section{INTRODUÇÃO}

O Corpo de Bombeiros Militar de Pernambuco (CBMPE) é uma instituição pertencente à administração pública direta, com previsão constitucional de sua subordinação aos Estados, inserido no rol de instituições responsáveis pela segurança pública, segundo o art. 142 da Constituição Federal (BRASIL, 1988). Constituída como órgão integrante da Administração Pública Direta, sendo custeado com a arrecadação de impostos, taxas, contribuições de melhoria, os quais são parte da mais-valia produzida pela sociedade (BEHRING, 2010) ${ }^{3}$.

Os seus recursos são oriundos de repasses do Estado, dentre os quais se destaca a cobrança de taxas referentes ao exercício regular do poder de polícia ou o fato da população ter um serviço específico e divisível a sua disposição ou efetivamente fazer proveito, tais taxas componentes da atividade financeira do Estado com o objetivo de atender às necessidades públicas (SILVA, 2011). Neste sentido, o respeito à alocação eficiente dos gastos públicos fomenta uma análise da proporção que estes recursos representam do total das receitas públicas e do detalhamento das respectivas despesas públicas.

Os aspectos orçamentários e patrimoniais destes recursos possuem grande semelhança com a definição de fundos públicos, que são unidades orçamentárias previstas na própria Lei Orçamentária Anual, com dotação própria e destinação específica, sendo apresentado como um subterfúgio da escassez orçamentária provocada pelo cenário de crise presente.

\footnotetext{
${ }^{3}$ Segundo a autora, a releitura do papel da mais-valia de Karl Marx proporciona o entendimento atual dos Fundos Públicos, os quais desempenham papel cada vez maior na sociedade. A mais-valia continua sendo compreendida como o excesso de valor agregado nos meios de produção e que se transformou em lucro, juros ou renda, aquilo que o trabalhador produz e após receber a remuneração pelo trabalho (salário), sobra para o proprietário. Na releitura, um aumento dos tributos para a Estado extrai parcela maior da mais-valia produzida e pode inclusive extrair parte do trabalho necessário à subsistência do trabalhador, combater este aumento desproporcional demanda a alocação eficiente de recursos em benefício direto e indireto da maioria trabalhadora.
} 
A atual crise fiscal e econômica no Brasil teve seus reflexos também nos Estados brasileiros, se por um lado desde o ano de 2015 os empresários alertavam o governo federal do grande rombo das contas públicas, por outro 0 governo anunciava cortes no Programa de Aceleração do Crescimento e restrições aos Programas de Financiamento Estudantil, estratégias que influenciavam diretamente no desenvolvimento dos Estados (DE ARAUJO, 2017).

O endividamento da máquina pública para manter os serviços públicos e dar continuidade à política econômica intervencionista é outro fator que provoca o esgotamento do orçamento público, no exemplo de Pernambuco o período de 2000 a 2015 foi marcado pelo aumento de $200 \%$ da dívida pública, seguindo a tendência de todo os Estados (PINHEIRO, 2017).

Do ponto de vista nacional, no período de 2006 a 2011, a dívida líquida dos Estados aumentou em $\mathrm{R} \$ 111$, 4 bilhões, a União como credora de $\mathrm{R} \$ 84,7$ bilhões e os demais credores representando a parcela restante de 26,7 bilhões. Entretanto, as dívidas junto a união aumentaram em virtude do superávit primário (diferença entre as receitas e despesas, excetuando-se o os encargos da dívida) não ser capaz de amortizar a dívida, mas no segundo caso houve a realização de mais empréstimos junto aos demais credores (PELLEGRINI, 2012).

Segundo Santos (2017), a crise fiscal econômica que atinge o Brasil desde 2014 afeta também os municípios, como exemplo, ressalta-se os 92 que fazem parte do Estado do Rio de Janeiro, os quais no período de 2014 até 2016 apresentaram quedas nas receitas totais. Tal diminuição representa em média $9 \%$ considerado como fontes das receitas tributárias com $R \$ 15,4$ bilhões $(-12 \%)$, da transferência do Estado com $R \$ 15,5$ bilhões $(-13 \%)$, da transferência da União com $\mathrm{R} \$ 10$ bilhões $(-1 \%)$ e dos royalties do petróleo com $R \$ 2,9$ bilhões (-54\%).

Além deste cenário de crise, o orçamento não fornece margem de discricionariedade para o administrador público quanto ao financiamento 
previdenciário, devendo ser feito o aporte necessário ao fundo específico quando as contribuições dos servidores não forem suficientes para custear as aposentadorias e pensões, verificando-se no caso concreto do Rio Grande do Sul a necessidade de aporte de $40,4 \%$ da Receita Corrente Líquida (RCL) no ano de 2016, no caso de Pernambuco o aporte foi de 9,5\% da RCL, obrigando os Estados inscrever as dívidas em restos a pagar como fonte de financiamento público (MERCÊS, 2017).

No intuito de reduzir os impactos da crise, os Estados adotaram políticas fiscais para aumentar a arrecadação de seu principal tributo, o Imposto de Circulação (ICMS), mas tal medida mostrou-se inócua por não conseguir acompanhar o aumento dos seus níveis de endividamento, ou seja, os seus superávits em média não têm sido suficientes para evitar o acúmulo das dívidas (TABOSA et al, 2016)

De acordo com Pellegrini (2012), existe uma hegemonia da União como credora das dívidas públicas dos Estados, lastreada pela superioridade de orçamento da união em detrimento dos entes da Federação. A dívida de Pernambuco representa cerca $1,2 \%$ do total do endividamento dos Estados, os casos mais expressivos é São Paulo (37,8\%), Minas Gerais (15,0\%), Rio de Janeiro (13,3\%) e Rio Grande do Sul (10,7\%), que representam juntos cerca de $77 \%$.

Diante deste cenário de precariedade do orçamento, os fundos públicos podem ser entendidos como uma fuga já que possuem destinações específicas em áreas variadas, como o exemplo do Fundo de Participação dos Estados, Fundo de Participação dos Municípios, Fundo de Desenvolvimento da Educação no Brasil, ou seja, todos possuem um fim específico, instituído por lei.

As fontes de recursos dos fundos são tipicamente exemplificadas através de impostos e taxas, mas no atual contexto de economia globalizada e a fase do capitalismo, suas finalidades tendem a ser capturadas pelos interesses da classe burguesa (industriais, comerciantes, prestadores de 
serviços) quando por exemplo são direcionados para a aquisição de ativos de empresas que podem não dar o retorno esperado para a sociedade (ATHAYDE, 2014).

Assim, se por um lado os impostos por definição não possibilitam seu uso para uma finalidade específica, as taxas por definição são originadas de um serviço específico para o qual devem ser vinculadas, possibilitando do ponto de vista ideológico a devida parametrização dos gastos empreendidos e a efetiva transformação da população atingida por tais atividades.

Ao analisar as fontes de recursos das atividades desenvolvidas pelo CBMPE espera-se que possam fornecer um panorama do impacto no orçamento único do estado de Pernambuco, viabilizando decisão sobre a possível criação de um fundo específico. Neste sentido, a destinação das taxas arrecadadas, além de respeitar as características da sua destinação, pode contribuir para o uso eficiente dos recursos e possibilitar o gerenciamento individualizado das contas do respectivo órgão, indicando se o mesmo se encontra em superávit ou déficit orçamentário.

Considerando-se o contexto descrito anteriormente, este estudo analisa as receitas e as despesas orçamentárias dos últimos 5 anos do CBMPE, colocadas à disposição no site do portal da transparência do Governo do Estado de Pernambuco, com o objetivo de mostrar as possibilidades na criação do fundo.

Este trabalho científico foi dividido em cinco partes. Após essa breve introdução; apresenta-se o referencial teórico, onde são apresentados 0 CBMPE e as características jurídicas e contábeis das taxas públicas, bem como o embasamento teórico dos fundos públicos. A terceira parte trata o método e dos procedimentos metodológicos para coleta de dados. A quarta parte trata da discussão dos resultados encontrados. E, por último, são apresentadas as considerações finais da pesquisa.

\section{REFERENCIAL TEÓRICO}


Revista Científica do Corpo de Bombeiros Militar de Pernambuco

Artigo Publicado no Vol.05 N.13 - Edição Jul a Dez 2019 - ISSN 2359-4829

Versão on-line disponível em: http://www.revistaflammae.com

\subsection{Taxas Públicas do Corpo de Bombeiros Militar de Pernambuco}

A Constituição Federal através de seu art. 142, determinou que a administração do Corpo de Bombeiros Militares fosse competência dos Estados, pois integra o rol de instituições responsáveis pela segurança pública junto das Polícias Militares e Civis (SILVA, 2012).

A instituição possui a missão de preservar a vida, o meio ambiente e o patrimônio e, por ser um órgão militar de âmbito estadual. Também desempenha funções de ordem pública, além das ações de defesa civil, atuando em enchentes, inundações, incêndios, desabamentos, deslizamento de encostas, acidentes em geral e calamidades públicas (GONZALES et. Al. 2006).

As suas atribuições como órgão de segurança pública demandam legitimação no sentido de garantir à sociedade a segurança necessária para o seu pleno desenvolvimento. Assim, esta detém poder de polícia de intervir em situações em que a incolumidade pública esteja ameaçada, sendo este poder de polícia um dos requisitos para a instituição da taxa de polícia (HARADA, 2013). O desempenho efetivo das atividades de intervenção na sociedade com o cunho de defesa civil comumente é chamado de atividade operacional ou atividade fim, a qual por vezes é realizado com exposição a matérias tóxicos, infectocontagiosos, radiação, tóxicos, ruídos, frio, altas temperaturas, além de ficarem sujeitos a pressões e posições desconfortáveis (BRITO, 2017)

$\mathrm{Na}$ esteira de legitimação ao exercício do poder de polícia, Pernambuco possui uma legislação base para a cobranças das taxas decorrentes da fiscalização e utilização de serviços públicos, a Lei 7.750, de 27 de dezembro de 1977 (PERNAMBUCO, 1977), alterada principalmente pela Lei 11.185 de 22 de dezembro de 1994 (PERNAMBUCO, 1994), a qual traz como hipótese de incidência de tais exações a propriedade de imóvel residencial com área superior a $50 \quad \mathrm{~m}^{2}$ (exceção de apartamentos que pagam taxas independentemente do tamanho), propriedade de imóvel comercial com áreas 
diferenciadas e os serviços de vistoria técnica e análises de projetos de prevenção e combate a incêndio para obtenção de atestados de regularidades para desempenho de atividades comerciais, além de outras que não serão objeto deste estudo. Para fins de esclarecimento quanto a diferenciação da taxa com outra exação, a propriedade ensejadora da taxa não se confunde com a do Imposto sobre Propriedade Territorial Urbana, pois enquanto este está ligado a manifestação de riqueza do proprietário, aquela restringe-se aos riscos de incêndio e desabamento que tal imóvel proporciona a sociedade, sendo quantificado e qualificado com bases de cálculos distintas, mas mantendo assim relação direta com natureza da própria taxa (BALEEIRO, 2010).

Assim, no processo legislativo para criação das taxas, a relação entre os valores arrecadados e os efetivamente gastos na atividade prevalecem sobre 0 arbítrio do legislador, de maneira que os ganhos nunca poderão ser superiores aos gastos, pois assim estaria configurada a retirada compulsória de parcela da riqueza da sociedade sem a devida contraprestação, o que por definição seria imposto (HARADA, 2013). Sob outro aspecto referente às taxas, ao considerarmos a Norma Brasileira de Contabilidade Técnica Aplicada ao Setor Público - NBC T SP 00 Estrutura Conceitual (2016), com efeito para o ano de 2017, as receitas tributárias compreendem os recursos arrecadados pelo Estado em função de seu poder de império, dos quais se destacam os impostos, as taxas, as contribuições de melhoria, as contribuições especiais e os empréstimos compulsórios. Os recursos podem ser classificados nos que demandam contraprestação ou não, sendo sua distinção a necessidade de prestação de um serviço ou entrega de um bem pelo Estado, que pode ser precedido do reconhecimento patrimonial da obrigação.

As receitas tributárias são classificadas como sem contraprestação, pois não existe a obrigação de registrar um passivo para cada recurso arrecadado, mas este aspecto não o abona de prover ao contribuinte uma ação ou serviço na consecução do bem-estar social. Neste sentido, observa-se que o 
contribuinte ao transferir seus recursos não possui domínio sobre a geração de benefícios econômicos futuros ou potencial de serviços pelo Estado, os quais podem ser observados com a construção de rodovias, manutenção do Sistema Único de Saúde, dentre outras atividades.

De outra forma, a NBC T SP 01: Receitas de transação em contraprestação (2016), traz um conceito de restrição que deve ser observado pelos recursos arrecadados pelo Estado,

[...] 19. As restrições sobre ativos transferidos (doravante referidas como restrições) não incluem a exigência de que o ativo transferido, ou outros benefícios econômicos futuros ou potencial de serviços, seja devolvido ao transferente se o ativo não for utilizado no modo especificado. Desse modo, a obtenção do controle do ativo sujeito à restrição não impõe sobre o recebedor a obrigação presente de transferir os benefícios econômicos futuros ou o potencial de serviços a terceiros quando o controle do ativo é inicialmente obtido.

Observa-se que as restrições podem ser interpretadas como os valores arrecadados pela taxa decorrente do poder polícia, mas este não proporciona ao contribuinte o poder de exigir a devolução de seu produto caso não venha a necessitar dos serviços no período de um ano do pagamento da taxa, ou seja, caso o contribuinte não tenha sido envolvido em um incêndio ou tenha necessitado de atendimento pré-hospitalar do CBMPE, não terá direito a ressarcimento.

Entretanto, segundo o NBC T SP 01 (CFC, 2016), quando o contribuinte tem poder de exigir do órgão recebedor a execução do serviço e não o faz, deve ser verificado no histórico da instituição o histórico de demandas administrativas e judiciais para a devolução de tais recursos. Caso as instituições não representem um significativo valor, ainda sim teríamos uma restrição em essência. Neste caso, se por algum ato administrativo um veículo de combate a incêndio não tenha sido enviado para controlar o incêndio mesmo tendo sido acionado para tal, deve-se observar a proporção das demandas em relação ao total arrecadado e efetuar sua classificação como restrição. 
Assim, tanto do ponto de vista jurídico tributário como contábil, os recursos arrecadados pelas taxas possuem correlação direta com as atividades que o originaram e acabam trazendo implicações para sua alocação.

\subsection{Fundos Públicos}

Os Fundos especiais possuem fundamento na Lei Federal ํํ 4.320, de 17 de março de 1964, norma básica de Direto Financeiro e em seu art. 71 dispõe que "constitui fundo especial o produto de receitas especificadas que por lei se vinculam à realização de determinados objetivos ou serviços, facultada a adoção de normas peculiares de aplicação" (NEVES, 2014).

Tais instrumentos podem ser utilizados como potencializadores da autonomia financeira em órgãos específicos, como defendido no Decreto-Lei 200, de 25 de fevereiro de 1967, alterado pelo Decreto-Lei ํo 900, de 29 de setembro de 1969, quando no parágrafo $2^{\circ}$ do art. 172 apresenta que:

"[...] nos casos de concessão de autonomia financeira, fica o Poder Executivo autorizado a instituir fundos especiais de natureza contábil, a cujo crédito se levarão todos os recursos vinculados às atividades do órgão autônomo, orçamentários e extra-orçamentários, inclusive a receita própria" (BRASIL, 1969).

Do ponto de vista histórico, a descentralização do poder decisório nas políticas do estado está intimamente ligada à eficiência, segundo Arretche (2002):

Uma das grandes reivindicaçães democráticas dos anos de 1970 e
1980 consistia na descentralização das políticas públicas. A avaliação
unânime de que a excessiva centralização decisória do regime militar
havia produzido ineficiência, corrupção e ausência de participação no
processo decisório conduziu a um grande consenso - que reunia, na
verdade, correntes políticas à esquerda e à direita - em torno das
virtudes da descentralização. O fundo público passa a ser compreendido como uma ferramenta da administração para o alcance de seus objetivos oriundos da luta das classes burguesas e dos trabalhadores, a primeira desejando o pagamento de juros da dívida pública através dos resultados primários, enquanto a segunda deseja a implementação de políticas sociais. Todas estas políticas são fomentadas 
através da extração do excedente de trabalho da sociedade convertido para recursos do fundo (ROTTA; LAGO; ROSSINI, 2017).

Observa-se que a literatura adota uma divisão quanto aos fundos públicos. Por um lado o próprio orçamento passa a ser compreendido como fundo já que compõe todas as receitas arrecadadas pelo ente e suas destinações. Por outro lado, tem-se os fundos públicos especiais oriundos da descentralização orçamentária e da eficiência almejada pelo Estado na administração dos recursos com programas de trabalho específicos.

Conforme Pessanha (2016), o patrimônio de um ente público é administrado para a aplicação em diversas políticas governamentais, mas a criação do fundo possibilita aplicação de uma determinada parte dos recursos para uma política específica na consecução de um objetivo específico. Sob o ponto de vista orçamentário não existe uma relativização do conceito de unidade do orçamento públicos, mas sim o princípio de não vinculação, o qual pressupõe que os recursos arrecadados possuem destinações gerais, não podendo ser vinculados a certas atividades, salvo as legalmente existentes.

Entretanto, segundo Brettas (2012), existe um entendimento de que o fundo público acaba colocando todas as pessoas em condição de igualdade através do pagamento de tributos e na definição de como deve ocorrer seu uso. Tal viés acaba mascarando que o próprio fundo público é causa e consequência das lutas de classes, com o condão de produzir melhores ou piores condições para os trabalhadores

Segundo Salvador (2012), o fundo público possui papel preponderante nas relações entre o mercado e os trabalhadores, pois além de desempenhar funções macroeconômicas proporciona o financiamento de políticas sociais, clara demonstração das funções alocativas e distributivas do orçamento público. O principal fundo público capaz de promover estas transformações é o próprio orçamento, principal recebedor dos tributos arrecadados e que possui seus objetivos claramente descritos nas leis orçamentárias Plano Plurianual (PPA), Lei de Diretrizes Orçamentárias (LDO) e Lei Orçamentária Anual (LOA) 
Assim sendo, o fundo público, seja ele o geral ou específico, mostra-se com uma importante ferramenta de alocação específica para os recursos pública com o condão de proporcionar o uso eficiente do Erário e possibilitar a efetiva transformação da realidade almejada, mitigando o risco de seu programa específico não possuir dotação orçamentária por questões fiscais ou políticas.

\section{PROCEDIMENTOS METODOLÓGICOS}

Ao avaliar como efetivou-se a relação fontes de recursos e suas destinações com enfoque na importância dos fundos públicos, depara-se com o paradigma de como proceder a investigação. Em uma primeira análise, para os investigadores científicos o paradigma representa uma opinião da comunidade científica sobre determinados aspectos de modelos de investigação (SILVA, 2010).

Nesta esteira, busca-se fugir da dicotomia qualitativo/quantitativo, pois não se trata na verdade de elencar um método em detrimento do outro, mas sim de evidenciar quais são os objetivos a serem investigados, e assim, já que no caso em análise existe uma preocupação com os significados do fenômeno fontes de recursos na Administração Pública, levando em consideração as motivações e as representações sociais econômicas, tem-se como conclusão que o paradigma a ser utilizado é eminentemente qualitativo (SILVA, 2010).

Neste sentido, buscou-se incialmente o arcabouço teórico para embasar a figura do fundo público e das taxas decorrente do exercício do poder de polícia na busca de correlações e identificar as características de uma estrutura conceitual comum, pois segundo Demo (2005), a abordagem metodológica que enfatiza a relação entre os elementos é chamado de método estruturalista, buscando entender o funcionamento de tal sistema para então obter uma estrutura lógica aplicável a situações semelhantes. 
Por um lado tem-se a o método estruturalista para identificar o conceito entrelaçado pelos referenciais teóricos, por outro através da análise das despesas e receitas dos anos de 2013 até 2017, obtidas através do site Portal da Transparência do Estado de Pernambuco onde foram encontradas as planilhas de fontes e destinações de recursos para o CBMPE demonstra que o procedimento metodológico usado será o de pesquisa descritiva já que busca evidenciar as relações entre as variáveis, através do estudo das características da relação fonte e despesa (GIL, 2010)

Tais fontes e destinações foram catalogadas de acordo com o ano, com a fonte de recursos e os elementos da despesa em que foram executadas. $\mathrm{Na}$ primeira análise evidenciou-se a relação entre os anos e as fontes de recursos, mencionado o valor total por ano e as proporções de cada origem, quanto que na segunda análise cada ano foi separado dos outros e passou-se a verificar as fontes de recursos com as devidas despesas. Considerando que a quantidade de elementos de despesa existentes na execução orçamentária do CBMPE, optou-se por trabalhar com os códigos separadamente (ver Figura 2).

\section{APRESENTAÇÃO E ANÁLISE DOS RESULTADOS}

Os resultados são apresentados da seguinte maneira: (i) Evolução das receitas de custeio do CBMPE, (ii) Proporção entre as fontes de receitas e despesas no período de 2013 a 2017 do CBMPE, (iii) Fontes de recursos e sua destinação no ano de 2013 e dos demais anos de forma individualizada. A busca no banco de dados do portal da transparência do Estado de Pernambuco das destinações das receitas no âmbito do CBMPE compreendeu o período de 2013 a 2017, obtendo-se como resultado os dados abaixo: 
Revista Científica do Corpo de Bombeiros Militar de Pernambuco

Artigo Publicado no Vol.05 N.13 - Edição Jul a Dez 2019 - ISSN 2359-4829

Versão on-line disponível em: http://www.revistaflammae.com

Tabela 1 - Evolução das receitas de custeio do CBMPE de 2013 a 2017

\begin{tabular}{|c|c|c|c|}
\hline ANO & |Valor Total & Porcentagem & Fonte de Recurso \\
\hline 2017 & 0 & $0,00 \%$ & ADESÃO 006/15-CP ARP 009/15-SDS/PE \\
\hline 2017 & 78.699 .995 & $28,92 \%$ & 0101 - RECURSOS ORDINÁRIOS - ADM. DIRETA \\
\hline 2017 & 3.026 .788 & $1,11 \%$ & 0102 - RECURSOS DE CONVÊNIOS A FUNDO PERDIDO/CONTRATO DE REPASSE - ADM. DIRETA \\
\hline 2017 & 190.443 .111 & $69,97 \%$ & 0104 - RECURSOS DIRETAMENTE ARRECADADOS - ADM. DIRETA \\
\hline TOTAL & 272.169.894 & & \\
\hline 2016 & 192.336 .233 & $86,87 \%$ & 0101 - RECURSOS ORDINÁRIOS - ADM. DIRETA \\
\hline 2016 & 334.820 & $0,15 \%$ & 0102 - RECURSOS DE CONVÊNIOS A FUNDO PERDIDO/CONTRATO DE REPASSE - ADM. DIRETA \\
\hline 2016 & 28.736 .019 & $12,98 \%$ & 0104 - RECURSOS DIRETAMENTE ARRECADADOS - ADM. DIRETA \\
\hline 2016 & 240 & $0,00 \%$ & 0145 - RECURSO DO FUNDO ENFRENTAMENTO À VIOLÊNCIA \\
\hline TOTAL & 221.407.312 & & \\
\hline 2015 & 182.333 .600 & $93,28 \%$ & 0101 - RECURSOS ORDINÁRIOS - ADM. DIRETA \\
\hline 2015 & 13.135 .968 & $6,72 \%$ & 0104 - RECURSOS DIRETAMENTE ARRECADADOS - ADM. DIRETA \\
\hline TOTAL & 195.469 .568 & & \\
\hline 2014 & 9.696 .283 & $5,42 \%$ & 0104 - RECURSOS DIRETAMENTE ARRECADADOS - ADM. DIRETA \\
\hline 2014 & 169.192 .009 & $94,58 \%$ & 0101 - RECURSOS ORDINÁRIOS - ADM. DIRETA \\
\hline TOTAL & 178.888 .292 & & \\
\hline 2013 & 168.880 .722 & $90,02 \%$ & 0101 - RECURSOS ORDINÁRIOS - ADM. DIRETA \\
\hline 2013 & 18.505 .900 & $9,87 \%$ & 0104 - RECURSOS DIRETAMENTE ARRECADADOS - ADM. DIRETA \\
\hline 2013 & 197.400 & $0,11 \%$ & 0119 - RECURSOS DECORRENTES DA OPER. DA CONTA ÚNICA PARA PROJETOS DE RESP. SOCIAL \\
\hline$\overline{\text { TOTAL }}$ & 187.584 .022 & & \\
\hline
\end{tabular}

Fonte: Portal da Transparência do Estado de Pernambuco

No primeiro aspecto analisado sobre a (i) evolução das receitas de custeio do CBMPE e conforme demonstrados na Tabela 1, ao longo dos anos as receitas que custeavam as atividades da Corporação estavam lastreadas em recursos ordinários da administração direta, caracterizados por transferências constitucionais e legais para o Fundo de Participação do Estados e outros recursos que não possuem destinação específica. No ano de 2017 houve um aumento exponencial do uso de recursos diretamente arrecadados pela administração direta, dos quais se destacam as taxas arrecadadas pelo CBMPE em decorrência do poder de polícia, representando cerca de $70 \%$ dos gastos e demonstrando que a mesma poderia tornar-se auto-suficiente.

Os recursos oriundos da fonte 104 possuem a restrição para seu uso específico na atividade do CBMPE já que são compostos pelas taxas arrecadadas, por outro lado a fonte 101 são os recursos ordinários da administração pública oriundos dos fundos de participação dos Estados, fundo de educação, dentre outros. Assim sendo, quanto menos a instituição for dependente dos recursos ordinários, o Estado acaba ganhando margem 
Revista Científica do Corpo de Bombeiros Militar de Pernambuco

Artigo Publicado no Vol.05 N.13 - Edição Jul a Dez 2019 - ISSN 2359-4829

Versão on-line disponível em: http://www.revistaflammae.com

orçamentária (dotação) para desenvolver outras políticas governamentais já que tais recursos não possuem a restrição para a sua alocação em programas específicos.

Pode-se também compreender que em respeito a relação direta existente entra as taxas arrecadadas em função do poder de polícia e o seu devido uso no órgão responsável, a situação evidenciada no ano de 2017 facilita a identificação pelo cidadão do valor efetivamente gasto na atividade, ao proporcionar o acompanhamento "pari passu" da relação fonte versus destinação dos recursos.

Nota-se que houve uma grande diferença das fontes de recursos do ano de 2016 para o de 2017, proporcionalmente os recursos arrecadados saltaram de uma representatividade de $12 \%$ e valor de $\mathrm{R} \$ 29.000 .000,00$ (vinte e nove milhões de reais) para cerca de $70 \%$ do orçamento da instituição, com valor de $\mathrm{R} \$ 190.000 .000,00$ (cento e noventa milhões de reais). No mesmo período houve a publicação da NBCTSP 00 e NCTSP 01, trazendo o conceito de receitas sem contraprestação e de restrição, de forma que existe a possibilidade de tal publicação ter sido o fator preponderante para tal mudança.

Figura 1: Proporção entre as fontes de receitas e despesas no período de 2013 a 2017 do CBMPE

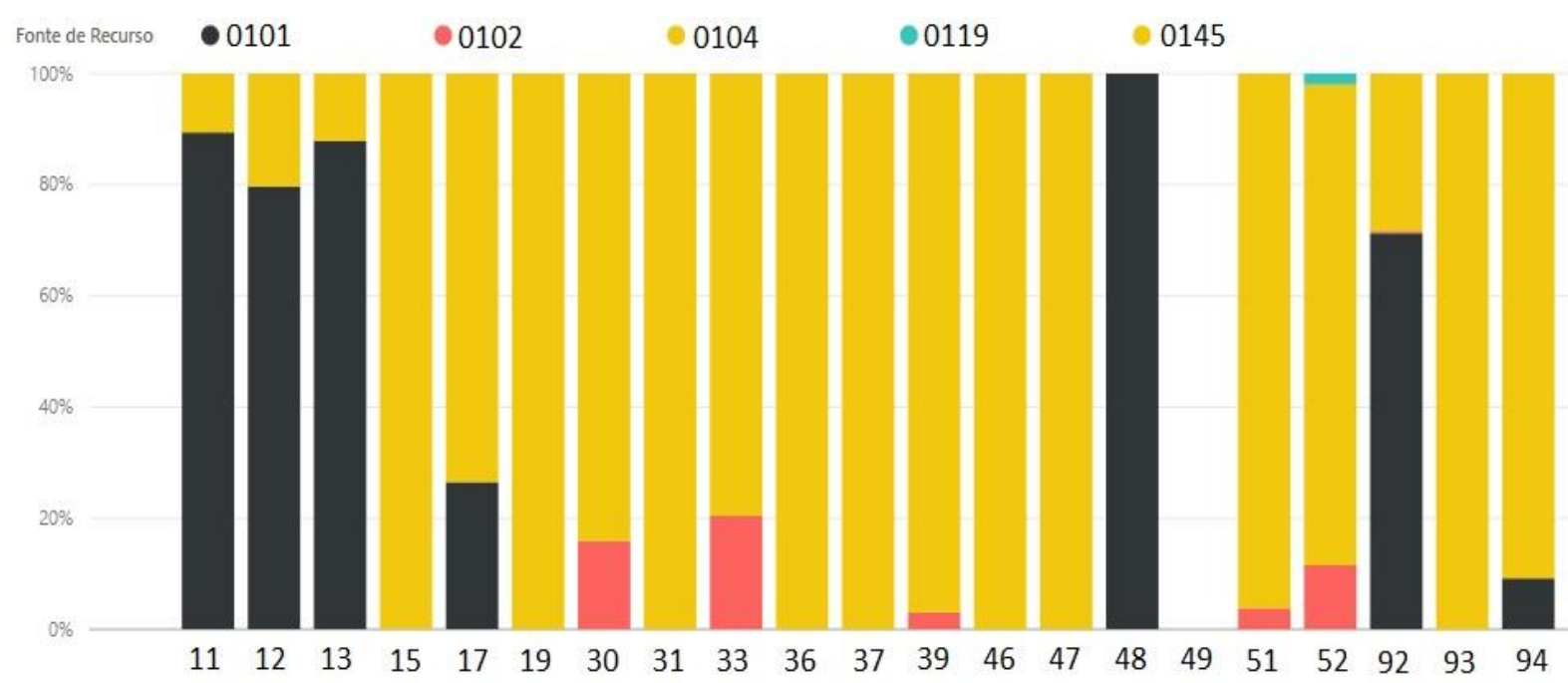

Fonte: Portal da Transparência do Estado de Pernambuco 
Revista Científica do Corpo de Bombeiros Militar de Pernambuco

Artigo Publicado no Vol.05 N.13 - Edição Jul a Dez 2019 - ISSN 2359-4829

Versão on-line disponível em: http://www.revistaflammae.com

No segundo aspecto analisado sobre a (ii) proporção entre as fontes de receitas e despesas no período de 2013 a 2017 do CBMPE e conforme demonstrados na figura 2 , os dados apresentam que a principal fonte de custeio foram as fontes de recursos originais, fonte de recursos arredados diretamente pela administração pública e através de convênio, mas para compreender os gastos é necessário verificar a relação de códigos de elementos de despesas existente na figura 2.

Figura 2: Elementos de despesa utilizados pelo CBMPE no período de 2013 a 2017

\begin{tabular}{l} 
DESTINAÇÕES \\
11 - VENCIMENTO E VANTAGENS FIXAS - PESSOAL CIVIL \\
\hline 12 - VENCIMENTO E VANTAGENS FIXAS - PESSOAL MILITAR \\
\hline 13 - OBRIGAÇÕES PATRONAIS \\
\hline 15 - DIÁRIAS MILITAR \\
\hline 17 - OUTRAS DESPESAS VARIÁVEIS - PESSOAL MILITAR \\
\hline 19 - AUXÍLIO FARDAMENTO \\
\hline 30 - MATERIAL DE CONSUMO \\
\hline 31 - PREMIAÇÕES CULTURAIS, ARTÍSTICAS, CIENTÍFICAS, DESPORTIVAS E OUTRAS \\
\hline 33 - PASSAGENS AÉREAS DESPESAS COM LOCOMOÇÃO \\
\hline 36 - OUTRIS SERVIÇOS DE TERCEIROS - PESSOA FÍSICA \\
\hline 39 - LOCAÇÃO DE MÃO-DE-OBRA \\
\hline 46 - AUXÍLIO ALIMENTAÇÃOO \\
\hline 47 - OBRIGAÇÕES TRIBUTÁRIAS CONTRIBUTIVAS \\
\hline 48 - OUTROS AUXÍLIOS FINANCEIROS - PESSOA FÍSICA \\
\hline 49 - AUXÍLIO TRANSPORTE \\
\hline 51 - OBRAS E INSTALAÇÕES \\
\hline 52 - EQUIPAMENTOS E MATERIAL PERMANENTE \\
\hline 92 - DESPESAS DE EXERCÍCIOS ANTERIORES \\
\hline 93 - INDENIZAÇÕES E RESTITUIÇÕES \\
\hline 94 - INDENIZAÇÕES E RESTITUIÇÕES TRABALHISTAS
\end{tabular}

Fonte: Portal da Transparência do Estado de Pernambuco

As figuras 1 e 2 foram criadas com dados do Portal da Transparência do estado de Pernambuco, apresenta-se a relação das fontes de recursos e suas destinações dos últimos cinco anos do CBMPE, quando se destaca o gasto com pessoal para pagamento de salários (códigos 11 e 12) e as obrigações patronais do Estado (código 13) através de fontes de destinação os recursos ordinários arrecadados, ou seja, recursos que poderiam ser usados para os 
demais fins da atuação do Estado estão sendo alocados para a instituição no intuito de pagar os militares e os civis.

Uma outra fonte de recurso bastante utilizada pela instituição é o convênio e, segundo Cardeal (2016) é quando uma outra instituição faz uma transferência voluntária de recursos, sendo tal temática abordada na Lei de Reponsabilidade Fiscal (LRF) - Lei Complementar oㅜ 101, de 04 de maio de 2000, trazendo o seguinte:

Art. 25. Para efeito desta Lei Complementar, entende-se por transferência voluntária a entrega de recursos correntes ou de capital a outro ente da Federação, a título de cooperação, auxílio ou assistência financeira, que não decorra de determinação constitucional, legal ou os destinados ao Sistema Único de Saúde.

Entretanto, segundo o $\S 1^{\circ}$ da referida lei, o Estado precisa respeitar algumas condições para recebimento de tais recursos, dentre as quais se destacam a observância dos limites da dívida consolidada e mobiliária, de operações de crédito, inclusive por antecipação de receita de inscrição de restos a pagar e principalmente de despesa total com pessoal. Desta forma, por apresentar-se como importante fonte de recursos para o CBMPE e o Estado uma gestão eficiente dos gastos públicos que respeitam também as condições impostas pela LRF tem o condão de ampliar as possibilidades de financiamento das atividades estatais. 
Figura 3: Fontes de recursos e sua destinação no ano de 2013

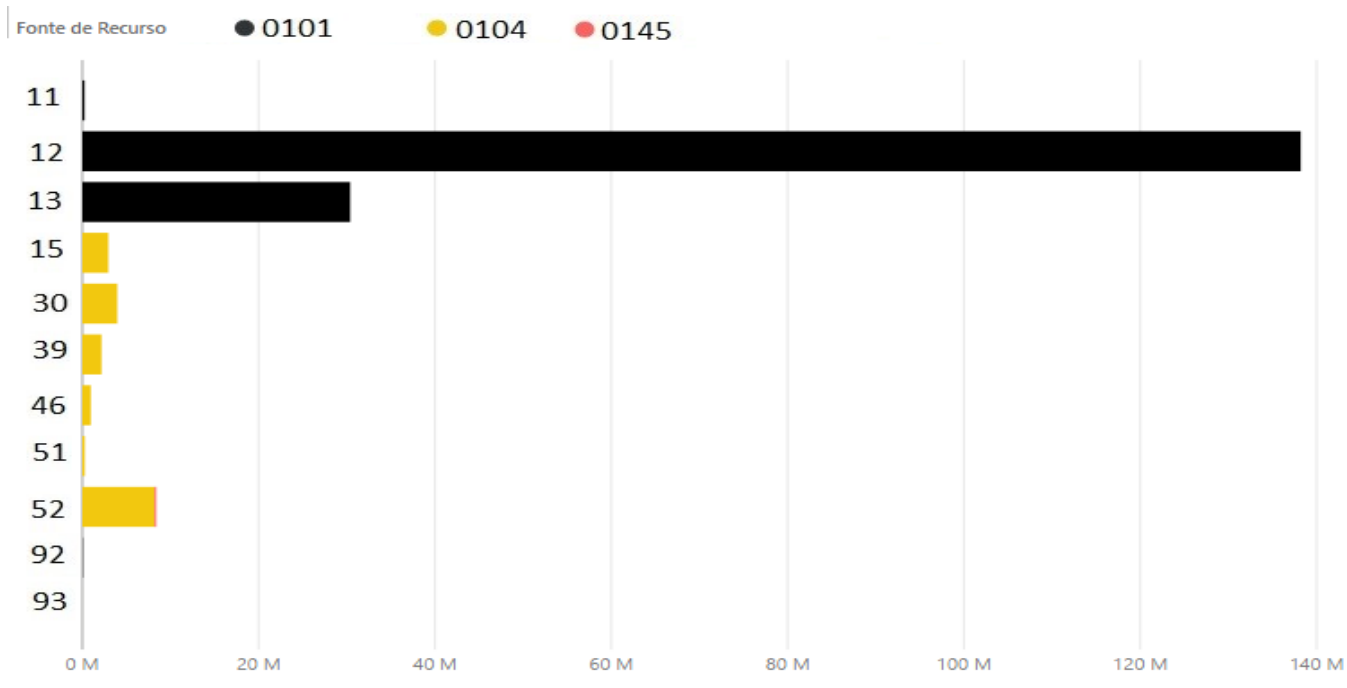

Fonte: Portal da Transparência do Estado de Pernambuco

O terceiro aspecto a ser analisado trada das (iii) fontes de recursos e sua destinação no ano de 2013 demonstradas na figura 3, de forma que se evidencia-se os gasto com pessoal e obrigações patronais (11, 12 e 13) completamente custeados por recursos originários do Estado, considerando que são despesas de caráter continuado e neste caso concreto demandam mensalmente valores superiores às demais despesas, a diminuta arrecadação das taxas de bombeiro foi determinante para a uso de tais fontes.

Dentre as depesas custeadas pelas taxas arrecadas e destinadas a fonte 104 (recursos diretamente arrecadados pela adminstração direta), a despesa com a compra de equipamentos e material permanente apresentou 0 maior montante o que pode demonstrar conhecimento dos conceitos de direito tributário de vinculação das taxas para sua atividade fim, bem como uma expansão das atividades através da compra de equipamentos não evidenciada nos demais anos em análise. 
Figura 4: Fontes de recursos e sua destinação no ano de 2014

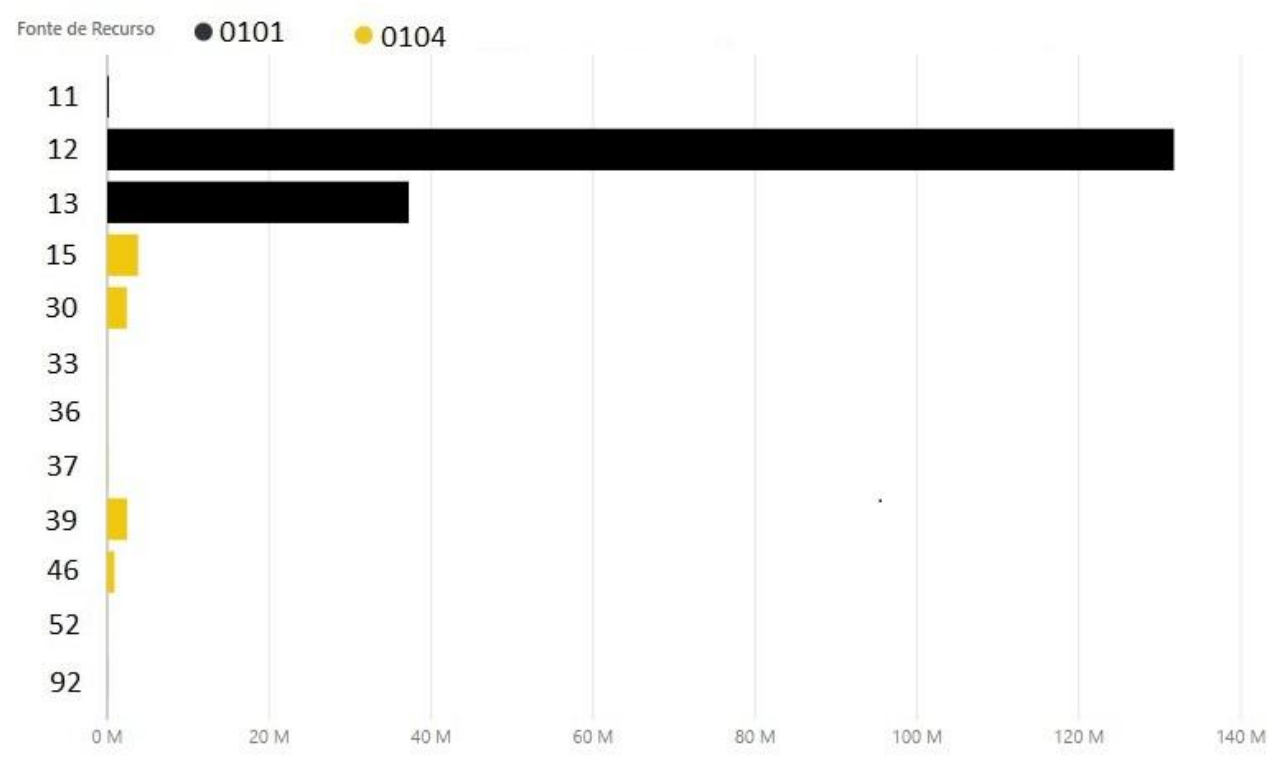

Fonte: Portal da Transparência do Estado de Pernambuco

Os dados da figura 4 que apresenta as (iii) fontes de recursos e sua destinação no ano de 2014 também identifica que o ano foi marcado pelo custeio de despesas de pessoal (11, 12 e 13) através de recursos originários, diminuindo a margem orçamentária do Estado, mas sendo necessária por conta da baixa arrecadação das taxas evidenciada na fonte recurso e 104.

Tratando-se dos recursos arrecadados e considerando o ano de 2014 como de eleição para Governador do Estado, é comum que as despesas de expansão como a aquisição de máquinas e equipamentos sejam diminuídas conforme se observa, mas no caso não houve nenhum gasto neste sentido e a principal despesa identificada foi a de diárias de militar no intuito de custear as atividades que extrapolem a área de atuação dos militares, como exemplo quando um militar que trabalha em recife deseja trabalhar no período de São João em Caruaru ou em alguma local que ainda não existe quartel, mas através de convênio com a prefeitura os militares desempenham suas atividades e ficam alojados sob a reponsabilidade do Município. 
Revista Científica do Corpo de Bombeiros Militar de Pernambuco

Artigo Publicado no Vol.05 N.13 - Edição Jul a Dez 2019 - ISSN 2359-4829

Versão on-line disponível em: http://www.revistaflammae.com

Figura 5: Fontes de recursos e sua destinação no ano de 2015

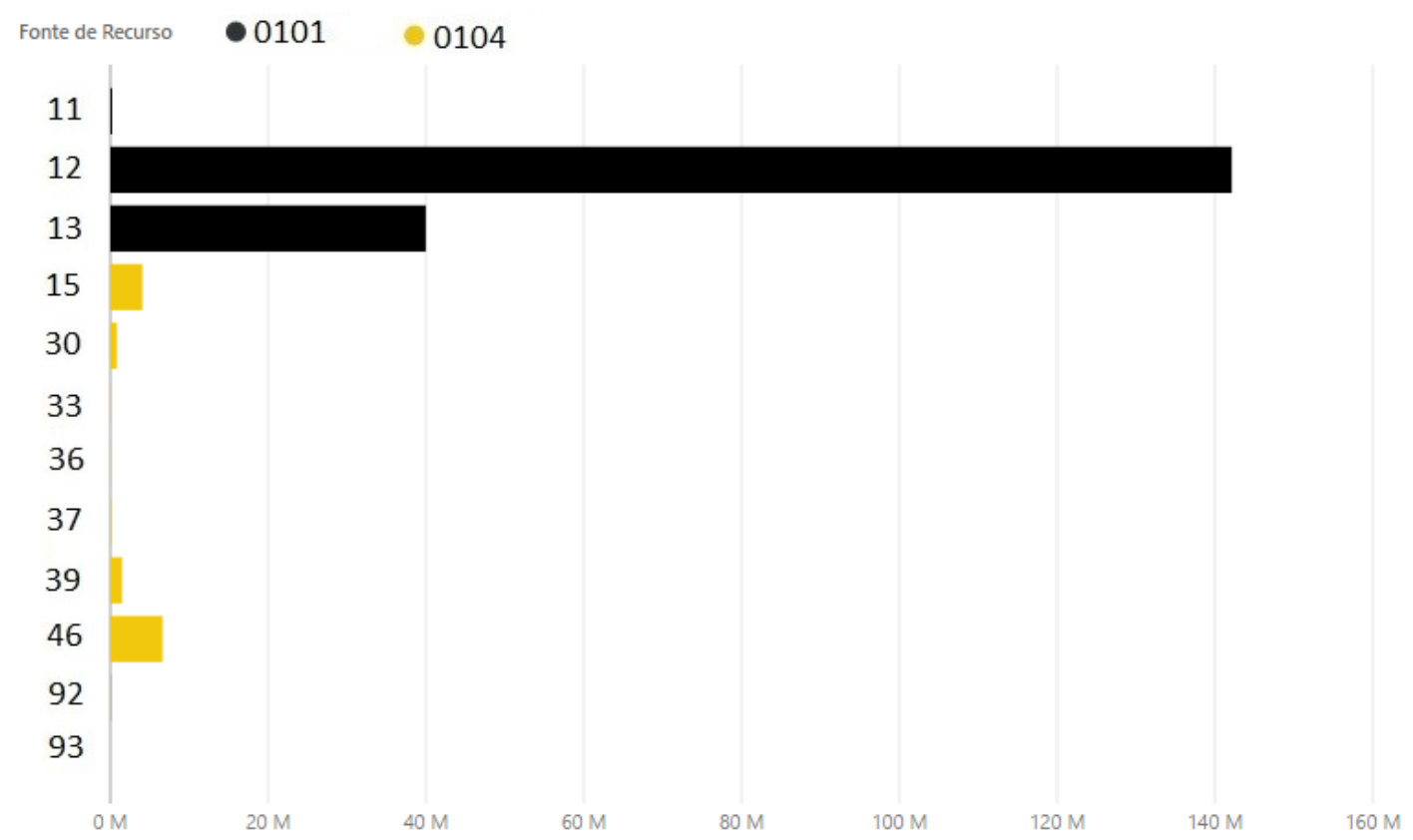

Fonte: Portal da Transparência do Estado de Pernambuco

Na figura 5 apresenta-se as (iii) fontes de recursos e sua destinação no ano de 2015, quando diante desta série histórica evidencia o custeio de pessoal com a fonte de recursos originário e o uso dos recursos arrecadados para o pagamento de diárias conforme observado no ano de 2013. Entretanto, neste ano sugere-se que uma alteração na lei de remuneração dos militares acarretando ao aumento do auxílio alimentação tenha sido o motivo dos gastos neste elemento de despesa (46) terem sido elevados. 
Revista Científica do Corpo de Bombeiros Militar de Pernambuco

Artigo Publicado no Vol.05 N.13 - Edição Jul a Dez 2019 - ISSN 2359-4829

Versão on-line disponível em: http://www.revistaflammae.com

Figura 6: Fontes de recursos e sua destinação no ano de 2016

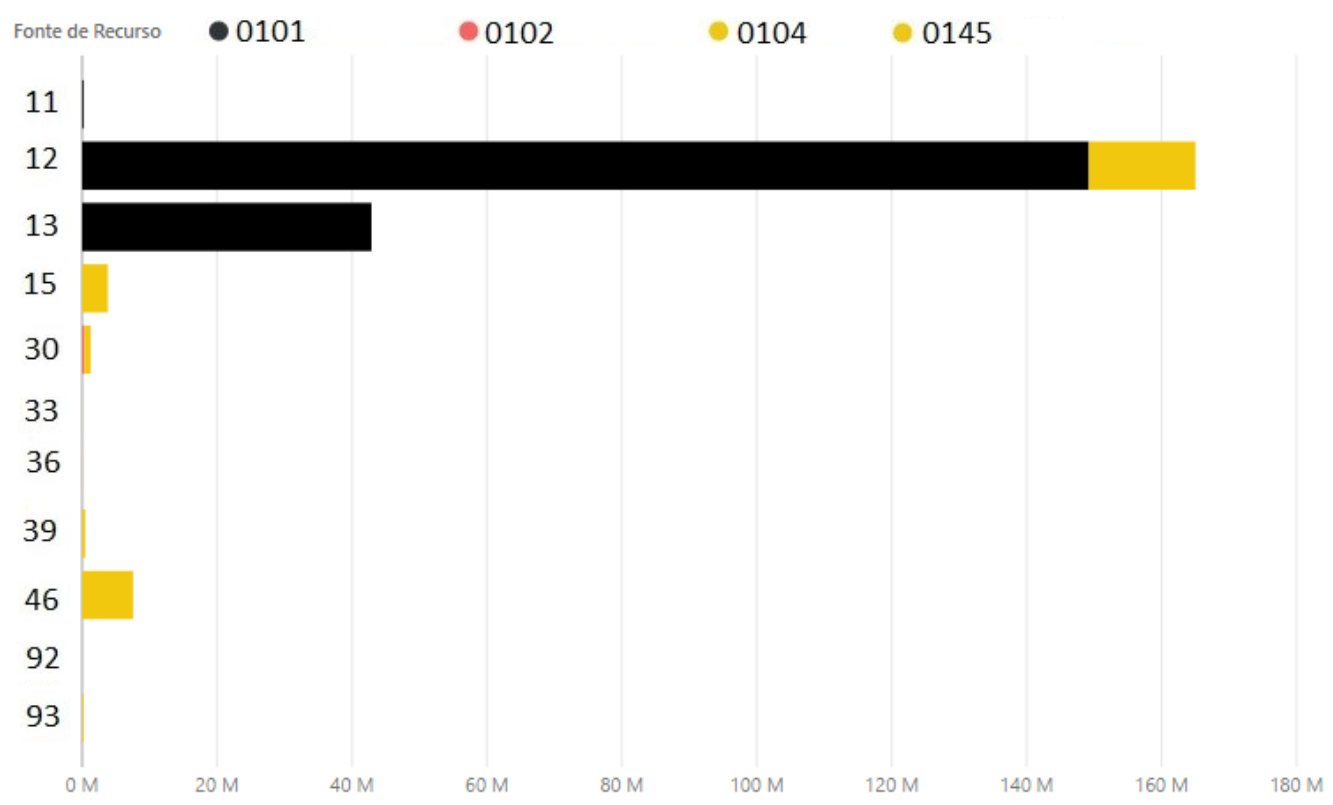

Fonte: Portal da Transparência do Estado de Pernambuco

A figura 6 também apresenta (iii) fontes de recursos e sua destinação, mas no caso o ano é 2016, pela primeira vez observa-se o uso da fonte de recursos arrecadados para o pagamento de despesas de pessoal no caso dos militares (12), tal fenômeno poderia representar o respeito aos preceitos constitucionais que originam as taxas públicas e proporciona ao Estado o uso das dotações orçamentárias de receitas originárias para outros programas e atividades, ampliando a atuação estatal na consecução do bem-estar social.

Além disso, os gastos com diárias e auxílio alimentação continuam representando grandes despesas custeadas pelos recursos arrecadados, permitindo que supostas dotações de outras fontes sejam usadas para outras atividades da administração pública. 
Figura 7: Fontes de recursos e sua destinação no ano de 2017

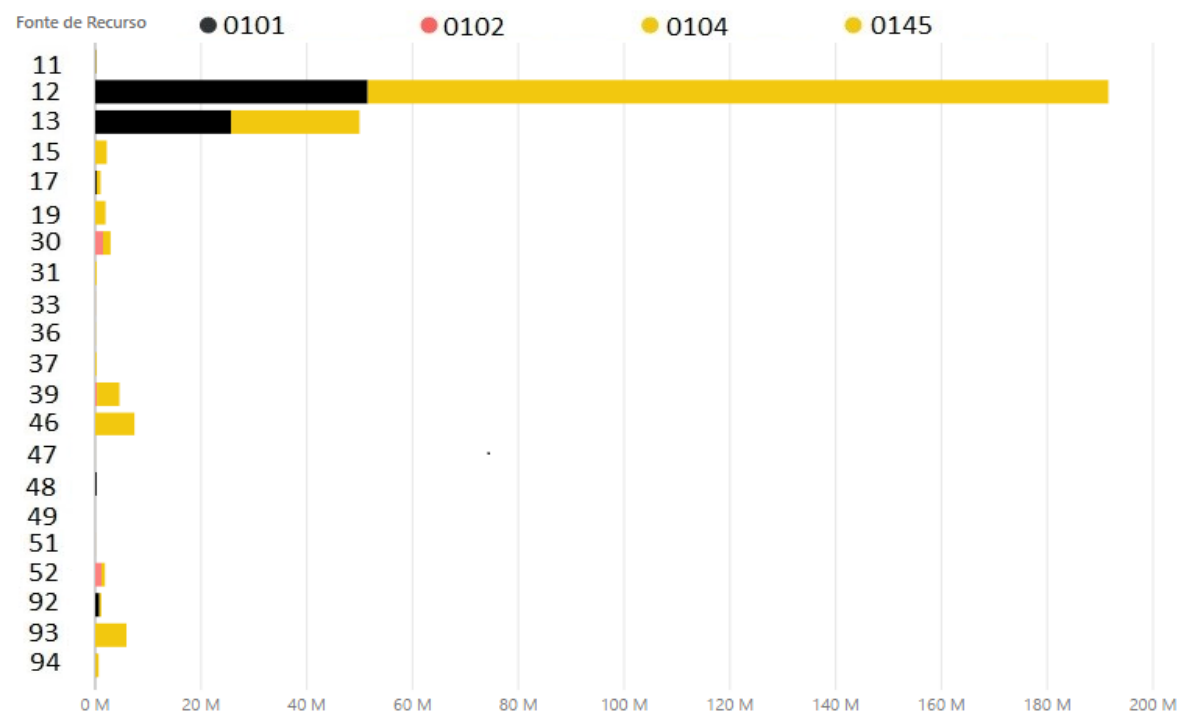

Fonte: Portal da Transparência do Estado de Pernambuco

$\mathrm{Na}$ figura 7 evidencia-se as (iii) fontes de recursos e sua destinação no ano de 2017, demonstrando-se a importante mudança na alocação de recursos pela administração pública no uso dos recursos arrecadados para o custeio de mais da metade das despesas com pessoal, principalmente no caso da folha de pagamento dos militares onde representa cerca de $R \$ 140.000 .000,00$ (cento e quarenta milhões) contra cerca de $\mathrm{R} \$ 50.000 .000,00$ (cinquenta milhões) dos recursos originários.

Uma hipótese para tal alteração pode ser descrita com a publicação no fim de 2016 das Normas Brasileiras de Contabilidade Aplicada ao Setor Público e a devida ênfase à alocação eficiente do gasto público com respeito às fontes dos recursos e suas destinações. A abordagem da NBCTSP nas condições de restrições para recursos arrecadados já discutidos neste trabalho possui relação também com os conceitos de direito tributário que norteiam as taxas públicas, dada a relação do fato gerador da taxa e o seu custeio que permite um acompanhamento da eficiência na alocação dos recursos. 


\section{CONSIDERAÇÕES FINAIS}

Observa-se que os fundamentos que subsidiam a criação das taxas públicas e sua relação com os fundos públicos passam a identificá-la como um resultado para a destinação específica desses recursos. Por um lado, dada a complexidade normativa e o enrijecimento das ferramentas orçamentárias, a criação do fundo demanda planejamento financeiro e alterações normativas. Por outro lado, a possibilidade de reverter os recursos para o gasto específico, mostra-se como ferramenta de gestão Estadual na alocação eficiente de recursos que justificam tais esforços.

As especificações dos recursos originários de taxas tratam-se de uma "restrição" (CFC, 2016), neste caso os recursos arrecadados deveriam ser empregados na atividade a qual se originaram, ensejando mudanças na alocação de recursos para os bombeiros em respeito aos novos preceitos que norteiam a Contabilidade Aplicada ao Setor Público.

Do ponto de vista gerencial, a criação de um fundo para o custeio das atividades da instituição demanda um controle orçamentário específico e acima de tudo fiscal, principalmente para o pagamento da folha de salários, maior dispêndio da administração pública. A vinculação explícita das taxas demandaria aportes eventuais do Estado caso as receitas fossem insuficientes para o custeio das atividades e de forma gerencial, a Administração Pública poderia estabelecer um cronograma de pagamento de tais tributos mais distribuído pelo ano, como medida mitigatória do suposto problema de ausência de caixa

A vinculação explícita também proporcionaria a transferência deste custo para os recursos diretamente arrecadados e caso fosse identificado déficit, as supostas causas poderiam ser a diminuição dos fluxos de pagamento ou os valores que são exigidos através das taxas públicas não estariam devidamente relacionados com os custos envolvidos na transação. A administração do fundo proporcionaria a administração pública ferramentas para devidamente repassar 
Revista Científica do Corpo de Bombeiros Militar de Pernambuco

Artigo Publicado no Vol.05 N.13 - Edição Jul a Dez 2019 - ISSN 2359-4829

Versão on-line disponível em: http://www.revistaflammae.com

o custo de tais atividades para a população de forma mais específica e de outra forma seria um fator limitante, quando efetivamente os valores arrecadados fossem superiores aos valores gastos na atividade

Ao analisar as contas da instituição, observa-se que o perfil deficitário vem diminuindo ao longo dos anos. No ano 2014 era de 90\% e em 2017 passou para $30 \%$. Sendo persistente a necessidade de alocação de recursos ordinários na sua atividade, ou seja, embora o Estado precise alocar recursos para o CBMPE, a criação de um fundo específico não afetaria supostos pode contribuir para gastos com novos investimentos e aprimoramento das atividades que ultrapassam os valores recebidos para custeio do CBMPE.

\section{REFERÊNCIAS}

ARRETCHE, Marta. Relações federativas nas políticas sociais. Educação \& Sociedade, v. 23, n. 80, p. 25-48, 2002.

ATHAYDE, Pedro Fernando Avalone. A disputa pelo fundo público no âmbito do financiamento esportivo brasileiro. Revista Brasileira de Ciências do Esporte, v. 36, 2016.

BALEEIRO, A., DERZI, M. A. M. Limitações Constitucionais ao Poder de Tributar. 3ed. Rio de Janeiro: Forense, 2010. p. 842.

BEHRING, E. R. Crise do capital, fundo público e valor. In: BOSCHETTI, Ivanete et al. (orgs.). Capitalismo em crise, política social e direitos. São Paulo: Cortez, 2010.

BRASIL. Constituição Federal, de 05 de outubro de 1988. Diário Oficial da República Federativa do Brasil, Poder Executivo, Brasília, 05 out. 1988.

. Lei n. 4.320, de 17 de março de 1964. Diário Oficial da República Federativa do Brasil, Poder Executivo, Brasília, 09 mai. 1964.

. Lei n. 5.172, de 25 de outubro de 1966. Diário Oficial da República

Federativa do Brasil, Poder Executivo, Brasília, 27out. 1966.

Decreto-lei no 200, de 25 de fevereiro de 1967. Diário Oficial da

República Federativa do Brasil, Poder Executivo, Brasília, 27 fev. 1967.

Decreto-lei no 900, de 29 de setembro de 1969. Diário Oficial da

República Federativa do Brasil, Poder Executivo, Brasília, 30 set. 1969. 
BRETTAS, Tatiana. Dívida pública: uma varinha de condão sobre os recursos do fundo público. Financeirização, fundo público e política social. São Paulo: Cortez, p. 93-122, 2012.

BRITO, José Mário Barbosa de et al. A clínica do trabalho e o desvelamento do traumático no trabalho bombeiro militar: fragmentos de um caso clínico. Revista do NUFEN, v. 9, n. 1, p. 148-163, 2017. Disponível em $<$ http://pepsic.bvsalud.org/scielo.php?script=sci_arttext\&pid=S217525912017000100010 >. Acesso em 04 de junho de 2018.

CARDEAL, Wagner Januário; BARCELOS, Marcos Aurélio. Fontes de recursos federais para ações de defesa civil. Revista Ordem Pública, v. 9, n. 1, p. 121132, 2016.

CONSELHO FEDERAL DE CONTABILIDADE. NBC T SP 00: Estrutura Conceitual para Elaboração e Divulgação de Informação Contábil de Propósito Geral pelas Entidades do Setor Público. Brasília (DF), 2016. (DF), 2016.

NBC T SP 01: Receita de transação sem contraprestação. Brasília

DE ARAUJO, Leonardo et al. O Ajuste Fiscal e a crise do novo desenvolvimentismo no segundo mandato De Dilma Rousseff. Revista Café com Sociologia, v. 6, n. 2, p. 354-374, 2017.

DEMO, Pedro. Metodologia científica em ciências sociais. 3.ed. São Paulo: Atlas, 1995

GIL, Antonio Carlos. Como elaborar projetos de pesquisa. 5. ed., São Paulo: Atlas, 2010.

GONZALES, R. M. B. et al. O estado de alerta: um estudo exploratório com o corpo de bombeiros. Escola Anna Nery Revista de Enfermagem, 2006; 10 (3):370 -377.

HARADA, K. Direito Financeiro e Tributário. 22ed. São Paulo: Atlas S.A., 2013. p. 320.

MERCÊS, Guilherme; FREIRE, Nayara. Crise Fiscal dos Estados e o caso do Rio de Janeiro. Geo UERJ, n. 31, p. 64-80, 2017.

NEVES, Herbert Ricardo Barbosa. A efetiva relação entre os investimentos realizados no Corpo de Bombeiros Militar do Estado de Goiás entre 2010 e 2013 e o fundo especial de reaparelhamento e modernização do corpo de 
bombeiros. $2014 . \quad$ Disponível em: <http://repositorio.bc.ufg.br/xmlui/handle/ri/10974>. Acesso em 08 jun 2018.

PINHEIRO, Raul Gomes; DE LIMA, Marcelo Ferreira. Fundo de Equilíbrio Fiscal: Qual o Principal Motivo de sua Criação? Revista Liceu On-Line, v. 7, n. 1, p. 115-134, 2017.

PERNAMBUCO. Lei $\mathbf{n}$ 7.550, de 20 de dezembro de 1977. Diário Oficial do Estado de Pernambuco, Poder Executivo, Recife, 21 dez. 1977.

. Lei n 11.185, de 22 de dezembro de 1994. Diário Oficial do Estado de Pernambuco, Poder Executivo, Recife, 23 dez. 1994.

PESSANHA, Lavínia Davis Rangel; DA SILVA FIGUEIREDO, Simone; CAMPAGNAC, Vanessa. Panorama dos Conselhos Municipais de Políticas Públicas do Estado do Rio de Janeiro. Anais, p. 1-18, 2016.

PELLEGRINI, Josué Alfredo. Dívida estadual, Textos para discussão. Núcleo de Estudos e Pesquisa do Senado. 2012. Disponível em: $<$ http://www12.senado.gov.br/publicacoes/estudos-legislativos/tiposdeestudos/textos-para-discussao/td-110-divida-estadual>.

ROTTA, Edemar; LAGO, Ivann Carlos; ROSSINI, Neusa. Disputa pelo Fundo Público Municipal: as políticas sociais na trajetória de duas décadas no Noroeste do Rio Grande do Sul. Textos \& Contextos (Porto Alegre), v. 16, n. 2, p. 495-510, 2017.

SANTOS, Angela Moulin S. Penalva; NAZARETH, Paula Alexandra. A Crise Fiscal e seus impactos nas relações interfederativas: o caso dos municípios fluminenses. Geo UERJ, n. 31, p. 1-33, 2017.

SILVA, J. A. Curso de Direito Constitucional Positivo. 36ed. São Paulo: Malheiros, 2012. p.787.

SILVA, Antônio Carlos Ribeiro da. Metodologia da Pesquisa Aplicada às Ciências Contábeis: orientações de estudos, projetos, artigos, relatórios, monografias, dissertações, teses. 3. ed. São Paulo: Atlas, 2011. 185 p.

SALVADOR, Evilásio. Fundo Público e o financiamento das Políticas Sociais no Brasil. Revista de Serviço Social, Londrina, V. 14, n.2, p. 04-22. 2012

TABOSA, Francisco José Silva et al. Reação fiscal ao aumento da dívida pública: uma análise para os estados brasileiros. Economia Aplicada, v. 20, n. 1, p. 57, 2016. 